\title{
Evaluation of Low-Temperature Cracking Performance of Asphalt Pavements Using Acoustic Emission: A Review
}

\author{
Behzad Behnia ${ }^{1}$, William Buttlar ${ }^{2}$ and Henrique Reis ${ }^{3, *}$ \\ 1 Department of Civil and Environmental Engineering, Clarkson University, Potsdam, NY 13699, USA; \\ bbehnia@clarkson.edu \\ 2 Department of Civil and Environmental Engineering, University of Missouri, Columbia, MO 65211, USA; \\ buttlarw@missouri.edu \\ 3 Department of Industrial and Enterprise Systems Engineering, University of Illinois, Urbana, IL 61801, USA \\ * Correspondence: h-reis@illinois.edu; Tel.: +1-217-333-1228 or +1-217-898-7063
}

Received: 11 January 2018; Accepted: 14 February 2018; Published: 21 February 2018

\begin{abstract}
Low-temperature cracking is a major form of distress that can compromise the structural integrity of asphalt pavements located in cold regions. A review of an Acoustic Emission (AE)-based approach is presented that is capable of assessing the low-temperature cracking performance of asphalt binders and asphalt pavement materials through determining their embrittlement temperatures. A review of the background and fundamental aspects of the AE-based approach with a brief overview of its application to estimate low-temperature performance of unaged, short-term, and long-term aged binders, as well as asphalt materials, is presented. The application of asphalt pavements containing recycled asphalt pavement (RAP) and recycled asphalt shingles (RAS) materials to thermal cracking assessment is also presented and discussed. Using the Felicity effect, the approach is capable of evaluating the self-healing characteristics of asphalt pavements and the effect of cooling cycles upon their fracture behavior. Using an iterative AE source location technique, the approach is also used to evaluate the efficiency of rejuvenators, which can restore aged asphalt pavements to their original crack-resistant state. Results indicate that $\mathrm{AE}$ allows for relatively rapid and inexpensive characterization of pavement materials and can be used towards enhancing pavement sustainability and resiliency to thermal loading.
\end{abstract}

Keywords: acoustic emission; thermal cracking; asphalt pavements; embrittlement temperatures; recycled asphalt pavements; recycled asphalt shingles; cooling cycles

\section{Introduction}

The majority of the roads in United States are surfaced with asphalt material, indicating the importance of this material in U.S. transportation infrastructure. In asphalt roads located in cold regions or in milder climate regions with large daily temperature fluctuations, a major form of deterioration is associated with the formation of low-temperature cracks, a.k.a., thermal cracks, in the pavement. Thermal cracks are categorized into two groups based on their formation mechanism: (1) "single-event thermal cracks", which occur in cold climates due to fast cooling rates; and (2) "thermal fatigue cracks", which develop after several cooling cycles in regions with a milder climate and large daily temperature fluctuations [1-4]. Thermal cracking phenomenon demonstrates itself as a group of parallel, evenly-spaced, transversely-oriented, surface-initiated cracks in pavements. A typical thermal cracking pattern in asphalt pavements is depicted in Figure 1a. As the temperature decreases, thermal stresses build up in the pavement due to the tendency of the "restrained" continuous layer of asphalt pavement to contract. The distribution of thermal stresses through the pavement thickness is 
non-uniform, with the highest stresses occurring at pavement surface, see Figure $1 \mathrm{~b}$. Thermal cracks happen when the thermally-induced stresses exceed the material fracture strength.
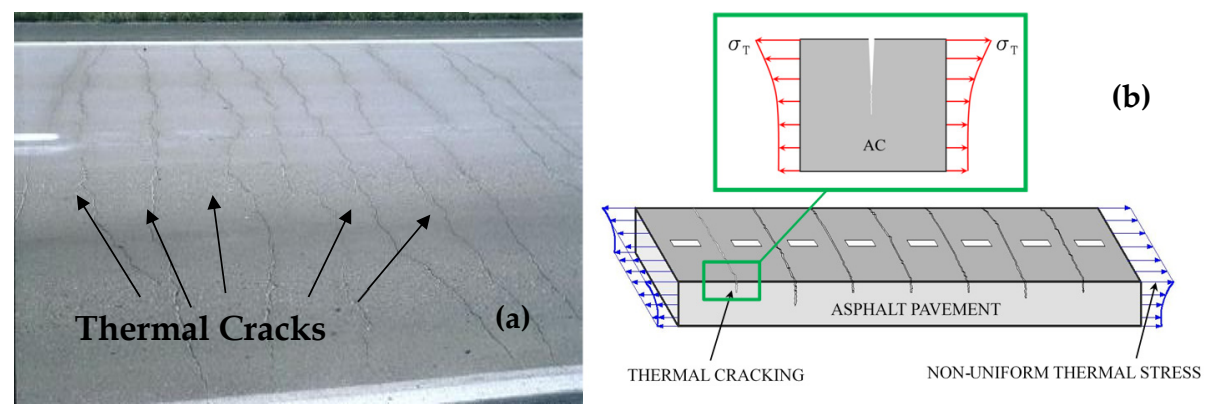

Figure 1. Thermal cracks as a result of oxidation; (a) typical thermal cracking pattern in asphalt pavement, (b) thermal cracking formation and non-uniform distribution of thermal stresses through the pavement thickness.

On the local scale, another source of thermal stresses in asphalt pavements is the thermal contraction mismatch between aggregates, i.e., crashed stone, and the surrounding asphalt mastic material. As the pavement temperature drops, asphalt mastic tends to contract more (often more than ten times) than the aggregate particles, causing increasing thermally-induced stresses in the pavement structure. At the same time as the temperature drops, the asphalt mastic becomes increasingly more brittle with less resistance against fracture. As a result, microcracks develop within the asphalt mastic when the thermally-induced tensile stresses overcome the fracture resistance of mastic material. In addition to mastic cracking, another type of damage, i.e., debondings, also occurs at low temperatures at the interfaces between asphalt mastic and aggregates, see Figure 2. Repair and rehabilitation of low-temperature cracks in pavements costs millions of dollars every year. In addition, damaged pavements also develop higher surface roughness, which leads to vehicle damage. A study by Islam and Buttlar showed that the presence of cracks in pavements would add over $\$ 300$ per vehicle per 19,000 km (12,000 mi) driven in user costs [5].

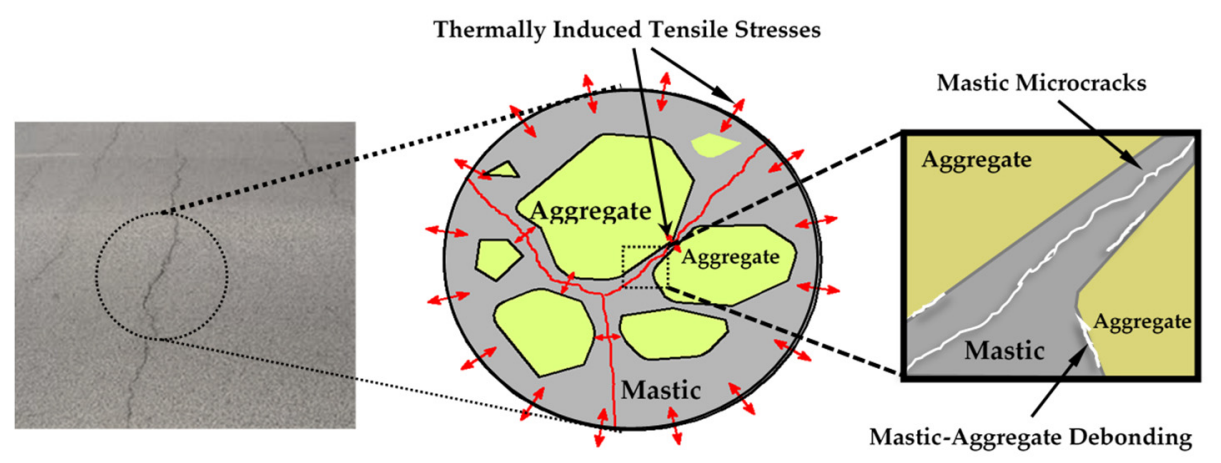

Figure 2. Schematic depiction of thermally-induced stresses within the asphalt mastic causing microcracks in the mastic and mastic-aggregate debondings.

Asphalt roads also suffer from oxidative aging [6,7]. Figure 3a shows two images of the same pavement section: one taken right after the construction and the other 19 months later when the pavement has already encountered some level of oxidative aging. Figure $3 \mathrm{~b}$ shows a schematic diagram illustrating the typical steep gradation of material properties (e.g., complex modulus) caused by oxidative aging at the pavement top material layer. Computer models have already been developed to estimate the change in material properties due to oxidative aging for given climatic conditions [7]. In addition to changing the asphaltenes to maltenes ratio [6], oxidative aging also increases the stiffness of the top material layers, see Figure $3 b$, which increases the pavement vulnerability to cracking in cold 
environments. Oxidative aging is an important issue in asphalt pavements that negatively affects low temperature cracking of asphalt materials. The higher the oxidative aging level of asphalt pavements, the higher the extent of thermal cracking damage in the material.

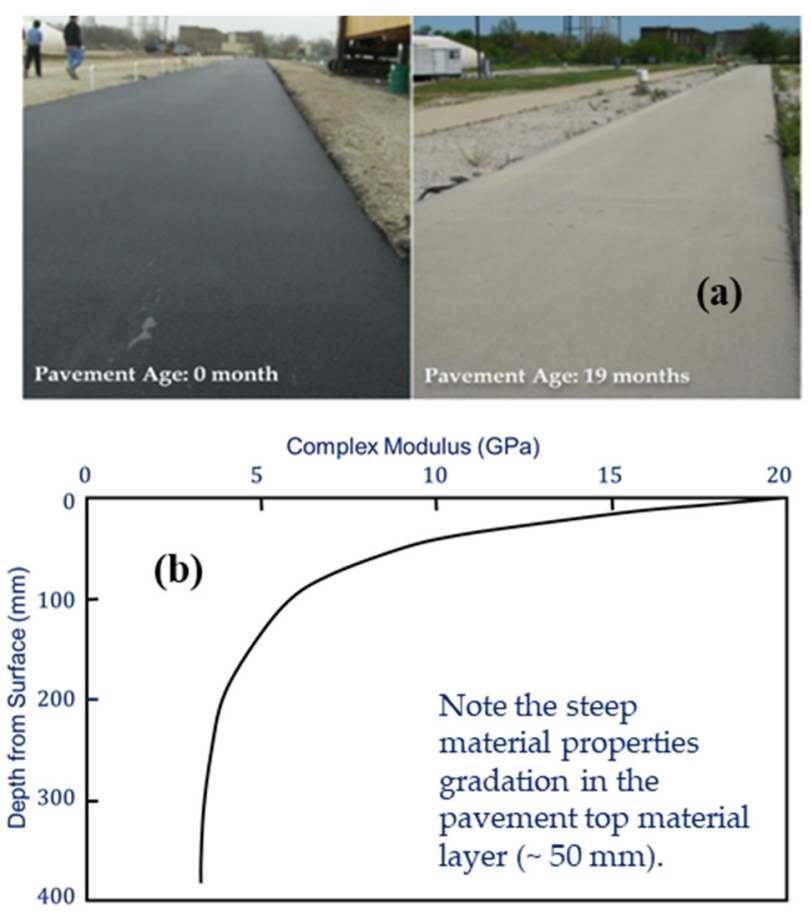

Figure 3. Oxidation of asphalt concrete pavements: (a) pavement section right after the construction (left), and the same pavement 19 months after construction (right); and (b) Schematic diagram illustrating the steep gradation of material properties (e.g., complex modulus) caused by oxidative aging at the pavement top material layer.

A great deal of research efforts has been directed towards the characterization and prevention of thermal cracks in pavement. The Superpave tests developed under the Strategic Highway Research Program (SHRP) in the 1990s have significantly improved the performance tests to assess the behavior of asphalt pavements by providing fundamental material tests over a broad range of production and service temperatures. However, the Superpave tests were not developed for (1) the characterization of highly modified binders, (2) the characterization of asphalt pavements containing recycled materials such as Reclaimed Asphalt Pavement (RAP) or Reclaimed Asphalt Shingles (RAS), and (3) the characterization of warm-mix materials. In addition to Superpave performance tests [8-12], studies conducted by several researchers [7,13-29] also provide valuable and significant insight into the estimation of asphalt materials low-temperature performance.

Acoustic Emission (AE) has been used extensively for damage detection and assessment of several materials including concrete, steel, wood, and rock. However, there has been limited application of AE for evaluating damage mechanisms in asphalt materials. Khosla and Goetz [21] used AE techniques to detect crack initiation and propagation in indirect tensile (IDT) specimens at $-23^{\circ} \mathrm{C}$. The study found that failure by fracture is indicated by a sharp increase in total AE counts, and that significant $\mathrm{AE}$ counts occur at about $80 \%$ of the peak load. Valkering and Jongeneel [22] used AE to monitor temperature cycling tests with restrained asphalt concrete specimens at low temperatures $\left(-10^{\circ} \mathrm{C}\right.$ to $-40{ }^{\circ} \mathrm{C}$ ). They observed that the repeatability of AE measurements is good, that the AE activity (i.e., number of events) correlates with the thermal fracture temperatures, and that the AE activity in restrained specimens at low temperatures is caused by defect initiation in the binder. Hesp et al. [23] used $\mathrm{AE}$ measurements to detect crack initiation and propagation in restrained specimens at low temperatures $\left(-32{ }^{\circ} \mathrm{C}\right.$ to $\left.-20^{\circ} \mathrm{C}\right)$. They concluded that the Styrene-Butadiene-Styrene (SBS)-modified 
mixes produced less AE activity than unmodified mixes. Li et al. [24-28] used AE techniques to characterize fracture in semi-circular bend asphalt specimens at low temperatures $\left(-20^{\circ} \mathrm{C}\right)$. They also concluded that large amounts of accumulated $\mathrm{AE}$ events occur at $70 \%$ of material strength, that the maximum intensity of $\mathrm{AE}$ peaks correlates with the development of macro-cracks, and that the location of AE events suggests that a several centimeter-sized process zone forms before the peak load. Nesvijski and Marasteanu $[29,30]$ used an AE spectral analysis approach to characterize fracture in semi-circular bend asphalt specimens at low-temperatures, and concluded that an AE approach could be used for evaluation of asphalt pavements. All of this research work led to the development of standards by the American Association of State and Highway Transportation Officials (AASHTO MP1, 1998; AASHTO TP1, 1999; AASHTO MP1A, 2001) [8-10] that allowed the estimation of the low-temperature performance of binders based upon their rheological properties.

\section{The Bending Beam Rheometer (BBR) Method}

For unmodified binders, the determination of cracking temperature is based on results from the bending beam rheometer (BBR) test in accordance with the standard test methods AASHTO TP1 [8]. Two asphalt binder parameters, i.e., the stiffness and the $m$-value, are determined based on the bending beam rheometer (BBR) test results at a loading time of $60 \mathrm{~s}$. The cracking temperature is defined as the temperature at which the stiffness reaches the value of $300 \mathrm{MPa}$ or the $\mathrm{m}$-value reaches the value of 0.3 , or, moreover, the temperature at which one of the specification thresholds is reached as temperature is decreased. The cracking temperatures determined using AASHTO TP1 have been found to be predictive of low-temperature cracking in asphalt pavements constructed using unmodified binders. However, AASHTO TP1 was found to grossly over predict low-temperature cracking performance for modified asphalt binders. As a result, for modified asphalt binders, additional testing using the direct tension test [3] (DTT) was proposed to address the case of binders with a stiffness higher than $300 \mathrm{MPa}$ and with an m-value greater than 0.3. Bouldin et al. [13] presented methods for predicting cracking temperatures using both the BBR and the DTT test data in the so-called dual instrument method (DIM).

These methods involve the use of sophisticated computer software for computing thermal stress in asphalt binders using the bending beam rheometer (BBR) data and estimating binder strength using the direct tension test (DTT). The dual instrument method (DIM) has been proposed as a standard method (MP1A) [10] for evaluating both modified and unmodified asphalt binders. To be able to use the MP1A, sophisticated equipment (DTT and BBR) and analysis software are required. Concerns have already been raised about the expensive nature of the MP1A approach, because its use has become prohibitive to many practitioners. Different approaches to alleviate these issues have also been proposed by Kim [15], and by Kim et al. [16], by Roy and Hesp [17], and by Shenoy [18], with some but not enough success to evaluate the low-temperature performance of asphalt materials.

For the practical low-temperature evaluation of binders, binder blends and mixtures for the purpose of formulation, design, control, and forensics, there is still a need for a test which is rapid, simple, compact, portable, and applicable to all modern binder types. Acoustic emission (AE) is a promising technique for evaluating embrittlement in asphalt binders, since it has been used successfully in other materials.

In this review paper, an acoustic emission (AE) approach is used to accurately and rapidly evaluate the thermal cracking performance of asphalt concrete materials including virgin, short-term, and long-term aged asphalt binders, as well as different asphalt concrete mixtures. A review of this technique along with applications of this approach are presented and discussed. For more details regarding experimental setups, etc., the readers are encouraged to refer to the appropriate citations.

\section{Acoustic Emission Based Evaluation of Embrittlement Temperatures}

The AE-based technique was implemented for low-temperature fracture assessment of asphalt materials. During the course of developing this testing approach, a wide range of asphalt binders and 
asphalt concrete materials with significantly different low-temperature cracking characteristics, as well as different oxidative aging levels (i.e., unaged, short-term aged, and long-term aged), were evaluated.

Figure 4a schematically shows the geometry of the developed test specimen for virgin (i.e., unaged) or aged asphalt binders, which consists of a thin layer of asphalt binder (with nominal dimensions of $125 \mathrm{~mm}$ long, $12 \mathrm{~mm}$ wide, and thickness of $6 \mathrm{~mm}$ ) bonded to a granite substrate. These asphalt binder specimens are prepared using aluminum molds, and they have the same dimensions as the standard Bending Beam Rheometer (BBR) specimens [9]. To make the binder specimen, the asphalt binder is poured into the aluminum mold wrapped in Teflon tape and placed on the granite slab, which is heated to the temperature of $135^{\circ} \mathrm{C}$, see Figure 4a. Prepared binder samples are allowed to cool down to room temperature for two hours before conducting the corresponding AE tests [31-37]. Figure $4 \mathrm{~b}$ shows the specimen after being tested using AE. Figure 5 a shows the binder test specimen along with the position of the $\mathrm{AE}$ sensors and the thermocouple. The geometry of AE specimens utilized for testing compacted asphalt concrete mixtures is shown in Figure $5 b$, in which the position of the AE sensor and the thermocouple is also shown. These specimens are typically semicircular, measuring $150 \mathrm{~mm}$ in diameter and $50 \mathrm{~mm}$ in thickness. This geometry was selected after examining several shapes and different sample thicknesses. In addition, the semicircular geometry is very practical and easy to make from cylindrical extracted field cores or laboratory gyratory compacted samples [36,37].

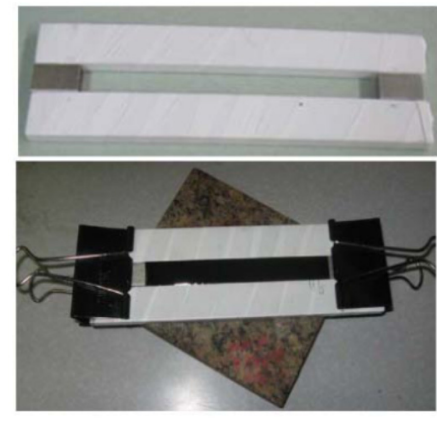

(a)

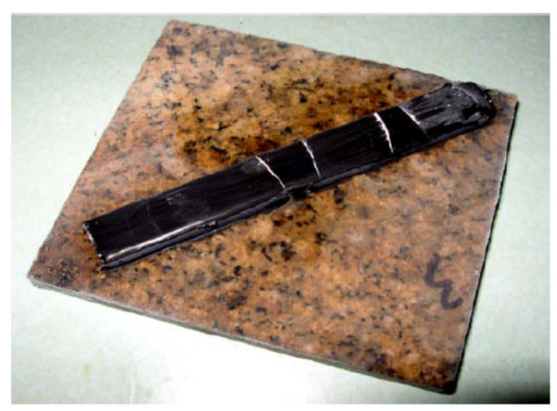

(b)

Figure 4. Fabrication of binder test samples: (a) top: molds for fabricating binder test samples; bottom: completed binder test sample in the mold; (b) typical visible crack patterns in asphalt binder test sample after AE testing. The binder samples have the same nominal dimensions as the specimens in the Bending Beam Rheometer (BBR) test (125 mm long, $12 \mathrm{~mm}$ wide, and $6 \mathrm{~mm}$ thick). The binder is poured into the mold seating on the granite (which has been heated to $135^{\circ} \mathrm{C}$ ) to assure good adhesion between the binder sample and the granite substrate.

Apart from different test sample geometries, the same testing set up and procedures are used for testing both asphalt binders and asphalt concrete specimens. To conduct the AE test, prepared specimens are placed inside the freezer and are cooled down from $20^{\circ} \mathrm{C}$ to about $-35^{\circ} \mathrm{C}$, or even to $-50{ }^{\circ} \mathrm{C}$, if necessary. A K-type thermocouple is placed on the specimens' surface to record the temperature of the samples. Because of the finite size of the test sample, there is a thermal lag at the beginning of the test, which becomes negligible (almost zero) at temperature lower than $-10^{\circ} \mathrm{C}$. Considering that the embrittlement temperature of almost all binders is below $-10{ }^{\circ} \mathrm{C}$, measuring the temperature at the specimen's surface appears to be a proper place $[3,32,33]$. Figure $5 c$ shows an AE test system, while Figure $5 \mathrm{~d}$ shows a temperature versus time plot while cooling the sample in a freezer. 


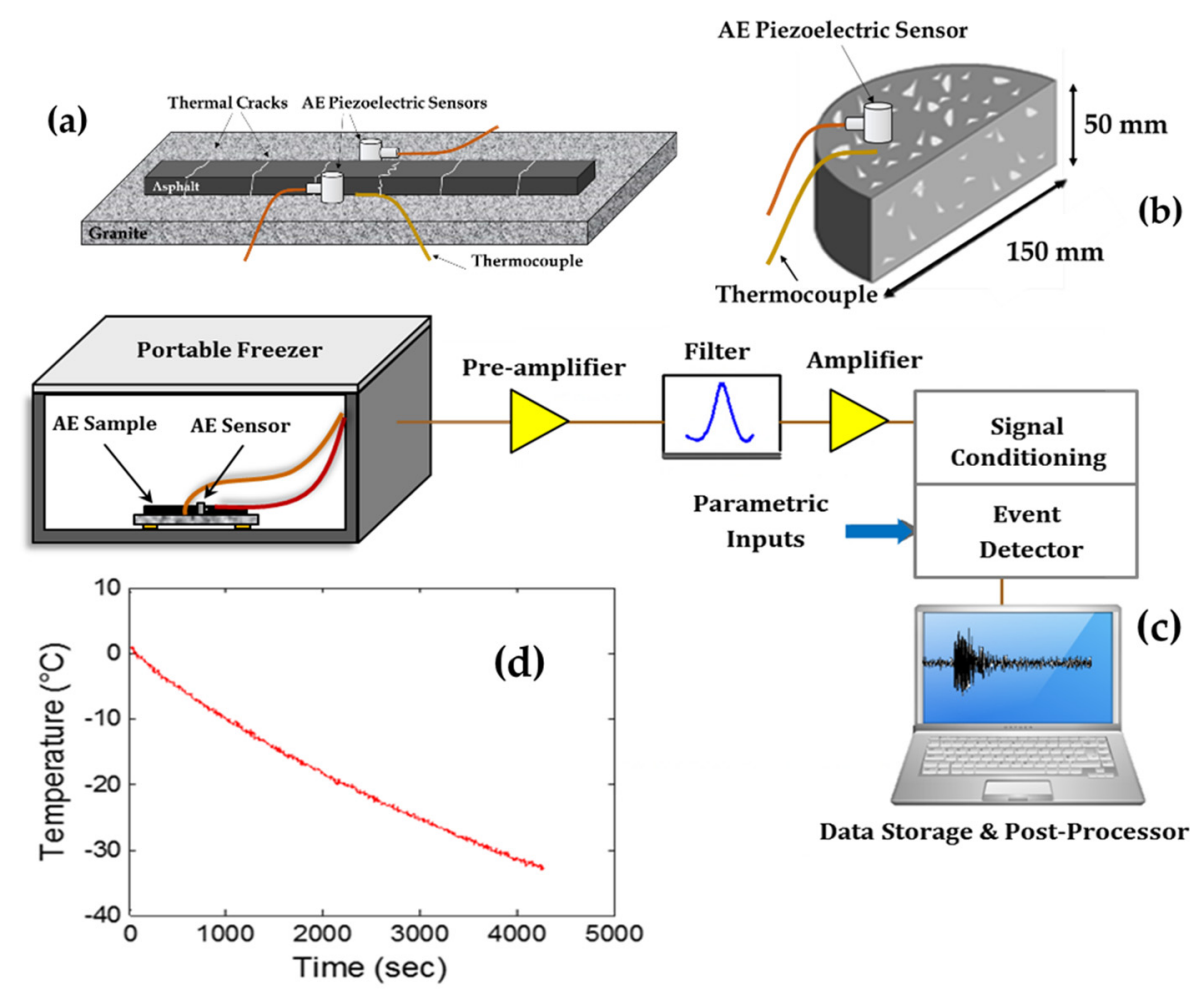

Figure 5. AE testing of asphalt materials; (a) asphalt binder test sample after AE testing showing two AE sensors and one thermocouple; (b) test sample for asphalt concrete mixtures; (c) AE test system for evaluating binders and asphalt concrete mixtures test samples; (d) typical temperature vs. time cooling plot for asphalt concrete mixture test samples.

Wideband AE piezoelectric sensors (Model B1025, Digital Wave Co., Denver, CO, USA) with a relatively flat sensitivity in the frequency band of $50 \mathrm{kHz}$ to $1.5 \mathrm{MHz}$ were utilized to monitor and record the acoustic activities of the samples during the test. AE stress waves were detected using the AE piezoelectric sensors, amplified, filtered, and then recorded. High-vacuum grease was used to couple the AE sensors to the test sample. AE signals were pre-amplified $20 \mathrm{~dB}$ using broad-band pre-amplifiers to reduce extraneous noise. The signals were then further amplified $21 \mathrm{~dB}$ (for a total of $41 \mathrm{~dB}$ ) and filtered using a $20 \mathrm{kHz}$ high-pass double-pole filter using the Fracture Wave Detector (FWD, Digital Wave Co., Denver, CO, USA signal condition unit. The signals were then digitized using a 16-bit analog to digital converter (ICS 645B-8) using a sampling frequency of $2 \mathrm{MHz}$ and a length of 2048 points per channel per acquisition trigger. The outputs were stored for later processing using Digital Wave software (Wave-Explorer TM V7.2.6) [9,31-37]. The Embrittlement Temperature ( $\left.\mathrm{T}_{\mathrm{EMB}}\right)$ of asphalt materials is defined as the temperature corresponding to the first high-energy AE event above a chosen energy threshold.

\subsection{Testing Asphalt Binders}

The performance of asphalt binders is extremely susceptible to changes in temperature. Binders are performance Graded (PG) with high- and low-temperature performance designations, which are based on the pavement's expected operating temperatures [11,12]. This grading designation allows for appropriate binders to be chosen to prevent temperature-driven pavement failures, such as rutting at high temperatures and cracking at low temperatures. Performance graded binders are designated as $P G X X-Y Y$, in which $X X$ is the high-temperature designation, which corresponds to the average temperature the binder is expected to encounter over a seven day period, and $Y Y$ is the low-temperature designation, which corresponds to the lowest expected pavement temperature [11,12]. 
In asphalt binder test samples, the thermal contraction coefficient of asphalt binders is several times greater than that of granite substrate. Therefore, as the binder specimen cools down, due to the differential thermal contraction between asphalt and granite substrate, thermal stresses build up in the restrained asphalt binder layer. At the same time, the tensile strength of the asphalt binder reduces with temperature. Eventually, when the thermal stress exceeds the strength of the binder material, thermal cracks develop, which are accompanied by the release of elastic strain energy in the form of transient mechanical stress waves, i.e., acoustic emissions. Both Figures $4 \mathrm{~b}$ and $5 \mathrm{a}$ show the asphalt binder test sample after the AE test, illustrating several thermal cracks [2,4,31-34].

The typical time domain response and the corresponding power spectral density curve of an $\mathrm{AE}$ event is shown in Figure 6. Analyses of AE activities of samples are performed on recorded AE signals and are associated testing temperature. The energy of the AE events was computed using Equation (1), in which $E_{A E}$ is the $A E$ energy of an event $\left(V^{2}-\mu s\right)$ with duration of time $t(\mu s)$ and recorded voltage of $\mathrm{V}(\mathrm{t})[31-34]$.

$$
\mathrm{E}_{\mathrm{AE}}=\int_{0}^{\mathrm{t}} \mathrm{V}^{2}(\mathrm{t}) \mathrm{dt}
$$
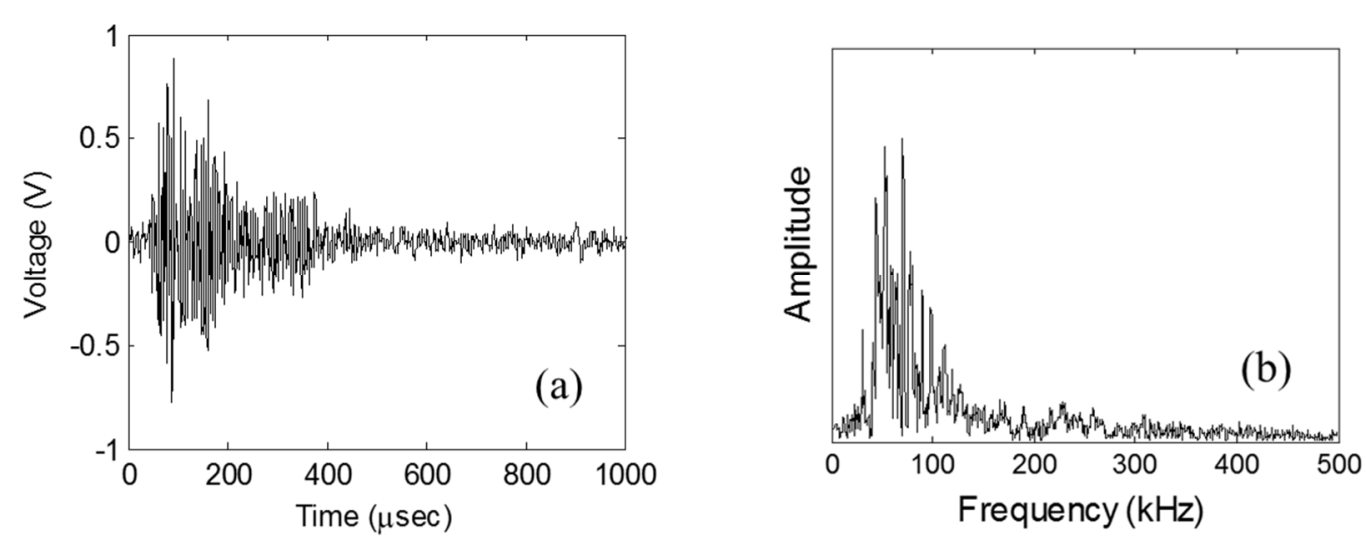

Figure 6. Typical acoustic emission event waveform (a) and corresponding spectral content (b).

A typical plot of AE cumulative events versus temperature for asphalt binders is shown in Figure 7, in which the energy of events versus temperature is also shown. In Figure 7, no events are recorded in the pre-cracking region, mainly because of the energy filtering process used. For each AE system gain, and using a binder of known cracking temperature, the energy threshold is selected (i.e., calibrated) to assure that the AE-obtained embrittlement temperature equals the known binder cracking temperature value grade, which is currently obtained using the binder rheological properties, i.e., the BBR methods. The AE-based embrittlement temperatures along the corresponding BBR-based critical cracking temperatures for various asphalt binders are provided in Table 1, in which, for comparison, the coefficient of variation $(\mathrm{COV} \%)$ is also shown for both methods. Please note that while the coefficient of variation is temperature scale-dependent, for the present application in which the embrittlement temperatures are in a relatively narrow range and sufficiently below zero, the COV was deemed to be a useful statistical parameter to describe the repeatability of the measurements obtained via the two approaches. Results from both approaches are also presented in Figure 8. Comparison of results also indicate that $\mathrm{T}_{\text {cracking }}(\mathrm{TANK})<\mathrm{T}_{\text {cracking }}(\mathrm{RFTO})<\mathrm{T}_{\text {cracking }}(\mathrm{PAV})$, in which RFTO and PAV stand for short-term and long-term aging, respectively, and TANK denotes virgin, i.e., unaged, binder. In Table 1 and in Figure 8, the term Rolling Thin-Film Oven (RTFO) indicates the binder was submitted to short-term aging, the Term Pressure Aging Vessel (PAV) indicates the binder was submitted to long-term aging (or a 7 to 10 year period), and TANK indicates virgin, i.e., unaged binder. 


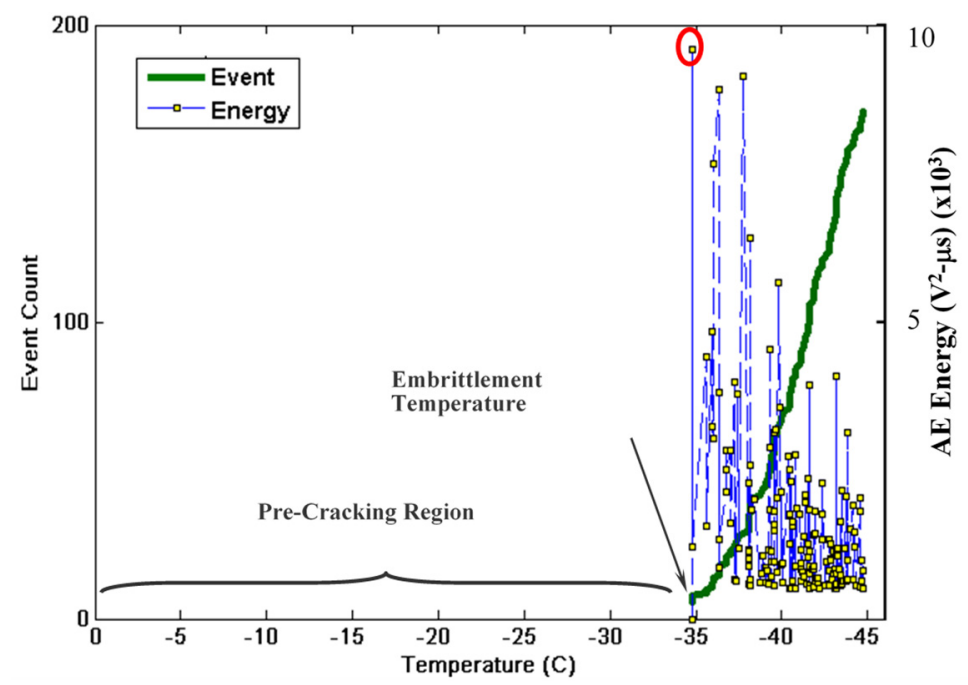

Figure 7. Typical experimental plot of cumulative events and energy versus temperature for asphalt binder test samples.

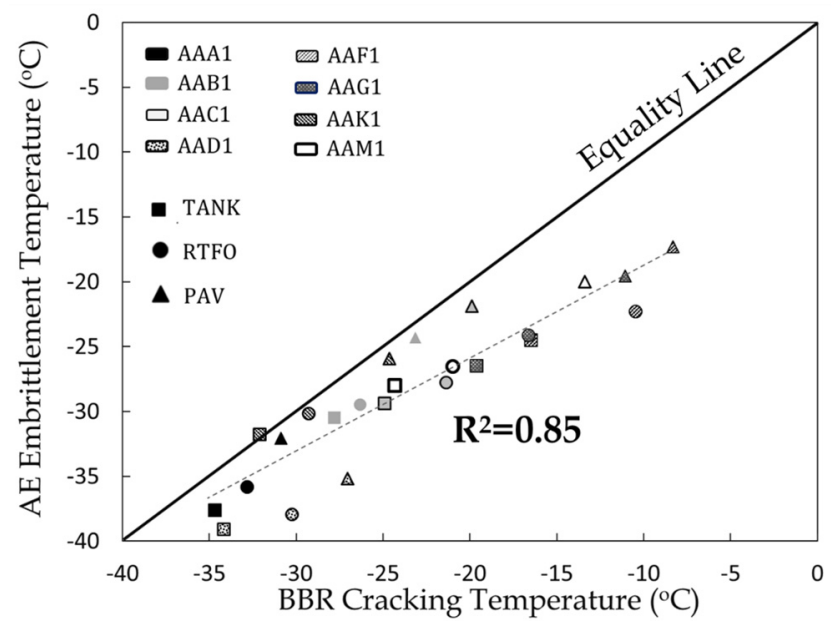

Figure 8. Correlation between AE embrittlement temperature and BBR-based cracking temperature, illustrating the conservative nature of the BBR-based cracking temperatures, see Table 1. 
Table 1. AE-based embrittlement temperature and BBR cracking temperatures of several different binders, each with three aging levels.

\begin{tabular}{|c|c|c|c|c|c|}
\hline \multirow{2}{*}{ Asphalt Binder * } & \multicolumn{2}{|c|}{$\begin{array}{l}\text { AE-Based Embrittlement } \\
\text { Temperatures }\left({ }^{\circ} \mathrm{C}\right)\end{array}$} & \multicolumn{2}{|c|}{$\begin{array}{c}\text { BBR Cracking } \\
\text { Temperatures }\left({ }^{\circ} \mathrm{C}\right)\end{array}$} & \multirow[b]{2}{*}{$\mathrm{T}_{\mathrm{BBR}}-\mathrm{T}_{\mathrm{EMB}}\left({ }^{\circ} \mathrm{C}\right)$} \\
\hline & $\mathrm{T}_{\mathrm{ENB}}\left({ }^{\circ} \mathrm{C}\right)$ & $\mathrm{COV}^{\#}(\%)$ & $\mathrm{T}_{\mathrm{BBR}}\left({ }^{\circ} \mathrm{C}\right)$ & $\mathrm{COV}^{\#}(\%)$ & \\
\hline TANK AAA1 (PG58-28) & -37.58 & 2.98 & -34.69 & 7.54 & 2.89 \\
\hline RFFO AAA1 (PG58-28) & -35.78 & 3.68 & -32.83 & 5.34 & 2.95 \\
\hline PAV AAA1 (PG58-28) & -32.09 & 3.68 & -32.83 & 8.07 & 1.20 \\
\hline TANK AAB1 (PG58-22) & -30.46 & 3.56 & -27.81 & 14.34 & 2.65 \\
\hline RFFO AAB1 (PG58-22) & -29.45 & 2.21 & -26.32 & 3.27 & 3.13 \\
\hline PAV AAB1 (PG58-22) & -24.33 & 3.25 & -23.13 & 7.92 & 1.20 \\
\hline TANK AAC1 (PG58-16) & -29.36 & 3.77 & -24.90 & 8.99 & 4.46 \\
\hline RFFO AAC1 (PG58-16) & -27.77 & 1.26 & -21.37 & 11.86 & 6.40 \\
\hline PAV AAC1 (PG58-16) & -21.86 & 5.30 & -19.90 & 11.66 & 1.96 \\
\hline TANK AAD1 (PG58-28) & -39.09 & 2.66 & -34.17 & 9.87 & 4.92 \\
\hline RFFO AAD1 (PG58-28) & -37.93 & 2.07 & -30.24 & 5.13 & 7.69 \\
\hline PAV AAD1 (PG58-28) & -35.19 & 2.79 & -27.03 & $3 . .35$ & 8.16 \\
\hline TANK AAF1 (PG64-10) & -24.47 & 4.74 & -16.49 & 7.35 & 7.99 \\
\hline RTFO AAF1 (PG64-10) & -22.29 & 3.35 & -10.47 & 14.33 & 11.82 \\
\hline PAV AAF1 (PG64-10) & -17.30 & 5.15 & -8.31 & 10.63 & 8.98 \\
\hline TANK AAG1 (PG58-10) & -26.48 & 3.56 & -19.63 & 17.05 & 6.84 \\
\hline RTFO AAG1 (PG58-10) & -24.12 & 2.55 & -16.63 & 10.45 & 7.49 \\
\hline PAV AAG1 (PG58-10) & -19.54 & 5.39 & -11.08 & 5.77 & 8.46 \\
\hline TANK AAK1 (PG64-22) & -31.76 & 3.24 & -32.12 & 9.00 & -0.36 \\
\hline RTFO AAK1 (PG64-22) & -30.15 & 2.76 & -29.29 & 3.94 & 0.83 \\
\hline PAV AAK1 (PG64-22) & -25.95 & 5.03 & -24.63 & 6.21 & 1.32 \\
\hline TANK AAM1 (PG64-16) & -28.01 & 2.67 & -24.32 & 4.58 & 3.70 \\
\hline RTFO AAM1 (PG64-16) & -26.52 & 3.60 & -21.01 & 7.32 & 5.52 \\
\hline PAV AAM1 (PG64-16) & -19.98 & 4.40 & -13.40 & 9.81 & 6.58 \\
\hline
\end{tabular}

* TANK, Rolling Thin-Film Oven (RTFO), and Pressure Aging Vessel (PAV) stand for unaged, i.e., virgin, short-term, and long-term aging, respectively. \# A minimum of four replicas was used to estimate average values and corresponding Coefficients of Variation (COVs).

Results also indicate that AE-based embrittlement temperatures are lower than the corresponding BBR-based critical cracking temperatures. This is not surprising, mainly because the AE-based embrittlement temperatures denote the measured values, while the BBR-base critical temperatures are based upon the binder's rheological material properties and include an inherent factor of safety to avoid low-temperature pavement cracking. For additional information, the readers are referred to References $[3,4,36]$. The developed AE-based approach was successfully employed to estimate the low-temperature performance grade of virgin, short-term, and long term-aged asphalt binders.

In addition to the initial transverse cracks shown in Figure 9, which divide the binder test sample into several blocks, Figure 9 also shows three-dimensional spiral cracks, which became visible only after removal of the top material from the test sample [38]. These spiral cracks are a result of the three-dimensional state-of-stress field that develops in each block (created by the transverse cracks) by the constraints imposed by the granite block. These spiral cracks were modeled as three-dimensional logarithm spirals using three parameters, (a spiral tightness parameter " $\mathrm{b}$ ", an apparent length scale parameter " $\mathrm{A}$ ", and the pitch angle " $\varphi$ ") that control how tightly and in which direction the spiral is wrapped. In addition to observing that the spiral pattern represents the crack trajectory with maximum energy release, it was also observed that the AE obtained embrittlement temperatures and fracture energy (obtained using indirect tension tests) are related to the spiral crack tightness parameter [38]. For additional information regarding modeling spiral cracks as the mode of failure in asphalt materials, the readers are referred to Behnia et al. [38]. 


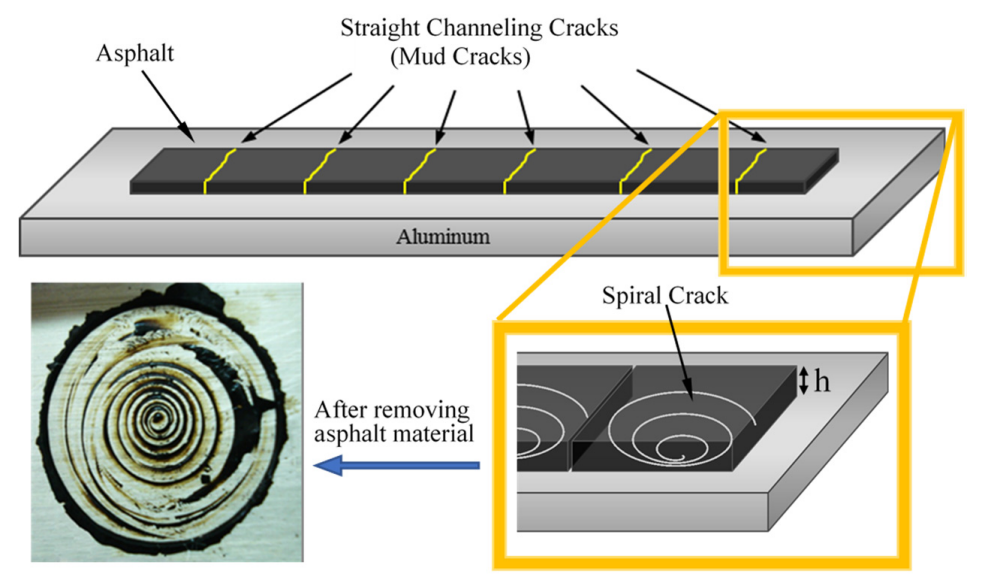

Figure 9. Asphalt binder showing the visible straight channeling cracks, i.e., mud cracks, and the spiral cracks that are only observed after the asphalt material is removed. The observed spiral cracks develop in each block due to the three-dimension state-of-stress induced by the thermal mismatch between the asphalt blocks and the granite substrate.

The promising AE results for low-temperature cracking performance of asphalt materials suggests that AE could be considered as a viable alternative for the ASHTO protocols, which estimate the low-temperature performance based upon the rheological binder properties. Furthermore, the AE approach has the advantage of being faster, having less variability, and capable of being used for all types of binders, including modified binders.

\subsection{Testing Asphalt Concrete Materials}

When AE asphalt concrete test samples are cooled down, thermally-induced stresses also develop in the test sample due to thermal contraction coefficient mismatch between the aggregates and the surrounding asphalt mastic. Different forms of thermal damage such as aggregate-asphalt mastic debondings, as well as thermal microcracks in the mastic, begin to occur in the sample when the local thermal stresses reach the local material strength. To visualize thermal damage in asphalt concrete test samples, X-ray computed micro-tomography (micro-CT) was employed using cubic asphalt concrete samples of one inch on-the-side, see Figure 10a. The X-ray micro-CT was conducted on asphalt concrete materials before and after two hours of conditioning the sample at $-50{ }^{\circ} \mathrm{C}$. Figure $10 \mathrm{~b}$ shows $\mathrm{X}$-ray tomographic images of the thermal damage in the sample with damaged areas circled in red. The following two types of damage can be identified by (1) microcracks within the mastic, and (2) debondings at the interface between aggregates and mastic. These thermally induced microdamages in the sample act as sources of acoustic activity during the AE test.
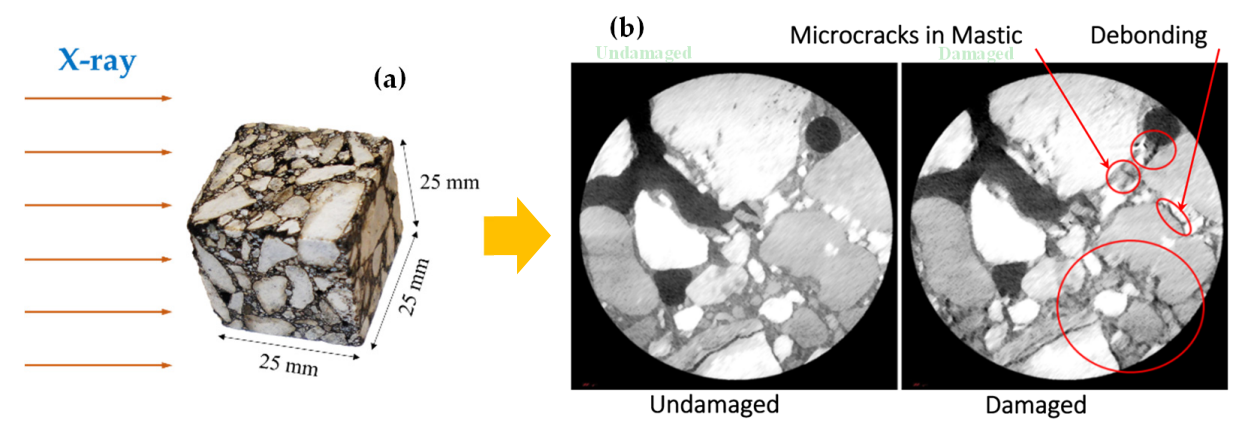

Figure 10. X-Ray micro-computer tomography imaging; (a) geometry and dimensions of used asphalt concrete sample; (b) images of undamaged (left) versus thermally damaged (right) asphalt concrete sample showing damaged regions. 
Based upon many experimental observations, a typical schematic diagram of AE cumulative events versus temperature for asphalt concrete samples was observed as shown in Figure 11. Four distinct regions exist in the AE cumulative events vs. temperature plot, namely: pre-cracking, transition, stable cracking, and fully cracked regions. In the "pre-cracking region", thermal stresses begin to accumulate in the sample. However, thermal stresses are not yet high enough to cause any thermal damage in the material. As a result, no AE events are detected within this region. Progressively increasing thermal stresses in the specimen eventually result in the formation of thermal microcracks in the material, which are accompanied by the release of mechanical transient stress waves, i.e., AE events. The second region, i.e., the "transition region", is defined as the point in time when thermal micro-cracking in the specimen, as indicted by higher energy events, begins to occur. The temperature corresponding to the event with the energy level above a predetermined threshold has been termed the "Embrittlement temperature $\left(T_{E M B}\right)$ ", as shown in Figure 12. For a given system amplification, the energy threshold is typically determined by calibrating the AE system by using samples made with a binder of a known cracking temperature, which is obtained by the traditional rheological-based methods (i.e., the BBR based methods).

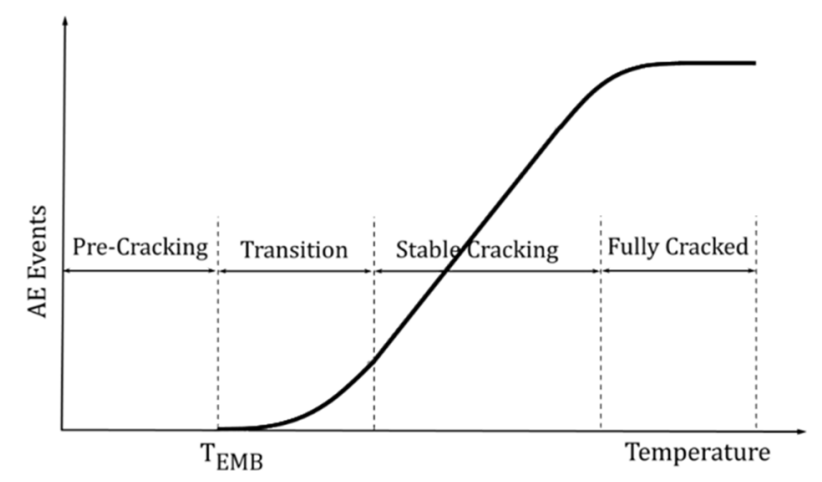

Figure 11. Schematic diagram of AE cumulative events vs. temperature showing four different regions for asphalt concrete materials.

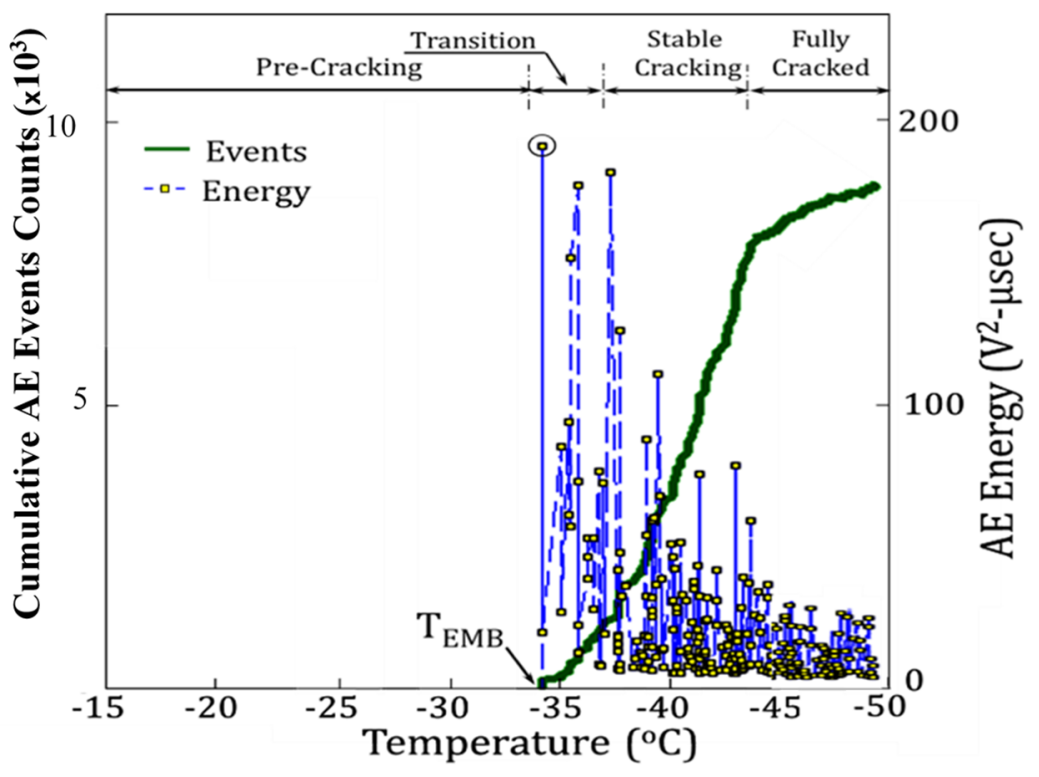

Figure 12. Typical plot of cumulative events and AE energy vs. temperature for asphalt mixtures.

The embrittlement temperature represents the onset of thermal damage in the asphalt concrete test sample. It is hypothesized that the embrittlement temperature represents a fundamental material 
property that is independent of material constraints, sample size (as long as a statistically representative volume or larger is used), and sample shape $[3,32,33,38,39]$. The "transition region" can be considered as the region where material behavior gradually changes from a quasi-brittle to a brittle state in which resistance to fracture is generally very low, allowing cracks to propagate readily. The "stable cracking region" usually initiates at a very low temperature, when the material is brittle and generates a significant amount of AE activity. The AE cumulative events versus temperature plot in this region usually has a steep slope that remains relatively constant. The "fully cracked region" starts right after the stable cracking region when the rate of AE activity of the samples begins to reduce until it reaches zero at the end of this region. Considering that the source of $\mathrm{AE}$ activities is the generation of new microdamage within the test sample, reduction in the rate of AE activity is an indication of the presence of plenty of microdamage in the sample. It should be noted that in AE-based tests, the fully cracked region is not usually observed unless the sample is cooled down to very cold temperatures, allowing all microdamage to fully develop within the test sample. Figure 12 shows a typical plot of cumulative event count and energy versus temperature for asphalt concrete test samples, where it is noted that the fully cracked region is not fully developed, mainly because only the embrittlement temperature is of interest.

\section{Thermal Cracking Evaluation of Asphalt Roads Containing Recycled Materials}

The use of AE-based approach to characterize pavements is now applied for asphalt concrete pavements containing recycled asphalt pavement (RAP) materials [36,37,40-42] and/or pavements containing materials from recycled asphalt shingles (RAS) [43]. The use of these recycled materials in asphalt roads has gained significant popularity in recent years, mainly because of environment and sustainability concerns. Additionally, using recycled materials can result in sustainable designs and cost savings by reducing the amount of virgin materials required in the production of new asphalt pavements. The AE-based technique was implemented to assess the effects of using recycled materials on thermal cracking performance of these asphalt pavements. Results showed that the AE-based technique could not only successfully evaluate the effect of recycled materials on low-temperature cracking performance of asphalt concrete, but also it could accurately detect the important phenomena of partial blending of recycled and virgin asphalt binders in asphalt mixtures.

Figure 13 presents the AE-obtained embrittlement temperature results of asphalt concrete samples of mixtures using the binder PG58-28 and containing the following different amounts of RAP: $0 \%$, $10 \%, 30 \%, 40 \%$, and $50 \%$. Each data presented in the plot is the average of at least four test replicates for each mixture material. Two sets of results are demonstrated: Figure 13a shows the AE results of mixtures with partial blending of RAP and virgin binder, whereas Figure 13b presents AE results of asphalt mixtures with proper mixing of RAP and virgin materials at higher temperatures with a longer mixing time. In both cases, it is observed that adding RAP increases the embrittlement temperature of the material suggesting that RAP mixtures crack at warmer temperatures. In case of partial blending, surprisingly, there is not significant distinction between $\mathrm{T}_{\mathrm{EMB}}$ of mixtures containing different amounts of RAP. This can be explained by noting that the AE testing procedure measures material properties on a local scale. If $\mathrm{AE}$ tests are conducted on a composite material system consisting of two types of materials, the $\mathrm{T}_{\mathrm{EMB}}$ of the composite will be the temperature at which the weaker of the two materials starts to undergo damage and fracture. In the case of partial blending mixtures, regardless of the amount of RAP in the mixture, since the unblended RAP materials experience thermal cracking first, the measured $\mathrm{T}_{\mathrm{EMB}}$ of those mixtures is in fact the embrittlement temperatures of the RAP material, which is the same for different mixtures with different amounts of RAP. However, in case of proper blending, it seems that the higher the amount of RAP content in the mixture, the warmer the cracking temperature of the mixture. Similar observations were noted for asphalt mixtures containing RAS materials [43]. Clearly, partial blending of recycled materials is an important issue. Application of AE-based test can significantly help reduce the partial blending in asphalt concrete and make the pavement more resilient to cooler temperature environments. 

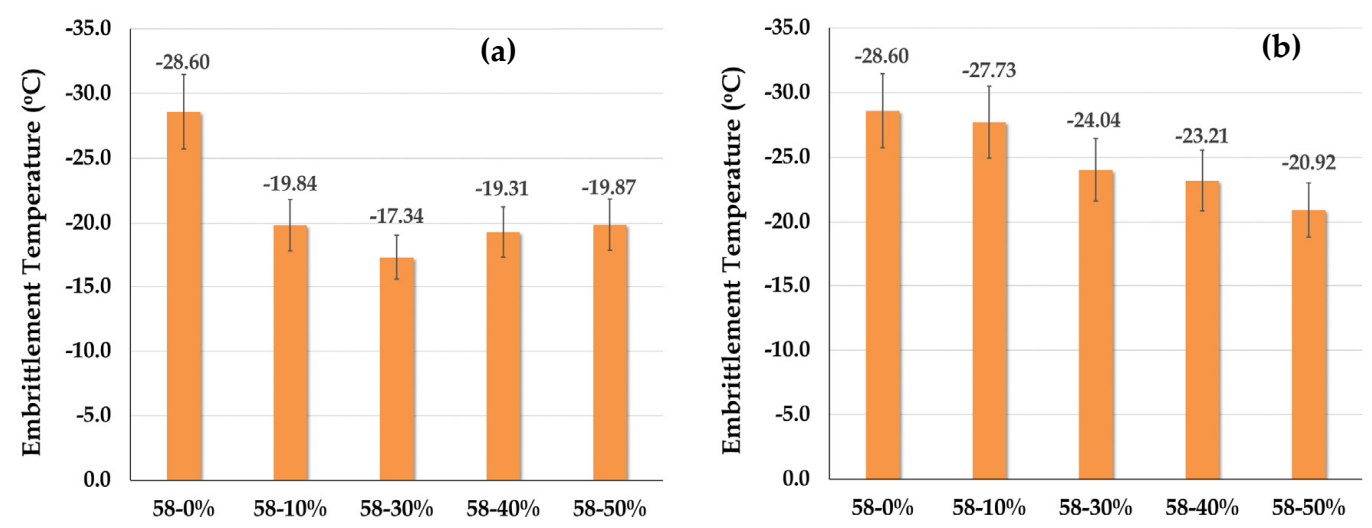

Figure 13. Embrittlement temperatures of PG58-28 mixtures containing different amounts of RAP: (a) mixtures with partial blending of RAP and virgin binders, (b) mixtures with proper blending of RAP and virgin binders.

\section{Low-Temperature Characterization of Asphalt Mixtures Subjected to Cooling Cycles}

In cold regions, cooling cycles cause thermally-induced micro-damages in the microstructure of asphalt concrete, which further reduces the asphalt pavements' resistance to fracture. Here, AE tests were conducted on field cores, as well as laboratory gyratory compacted samples, and the corresponding embrittlement temperature of samples were determined [44].

During thermal cycling of asphalt concrete, it was observed that asphalt concrete specimens generated $\mathrm{AE}$ activities before the previous minimum temperature (i.e., maximum thermal loading level) was reached. This phenomenon is known as the "Felicity effect", and is characterized by the presence of detectable AE activity during reloading of the material before the load level reaches the previous maximum applied load [45]. The Felicity effect observed in asphalt materials is illustrated in Figure 14, which shows the cumulative AE events versus applied thermal load. The loading path from $B$ to $C$ (unloading) and $C$ to $D$ to $E$ (reloading) clearly indicates the absence of $A E$ activity up to a loading level $\left(\mathrm{T}_{\mathrm{D}}\right)$, which is below the level of the previous loading cycle $\left(\mathrm{T}_{\mathrm{B}}\right)$. It should also be noted that another AE loading phenomenon, known as the Kaiser effect, may also take place if the mixture loses the ability of self-healing. The Kaiser effects occurs when no AE activity occurs until the previous maximum load level is reached, which makes the Kaiser effect a particular case of the Felicity effect (i.e., points B and D coincide). The Kaiser effect can be observed in highly oxidized mixtures and/or when no time is allowed between cycles for the self-healing to take place.

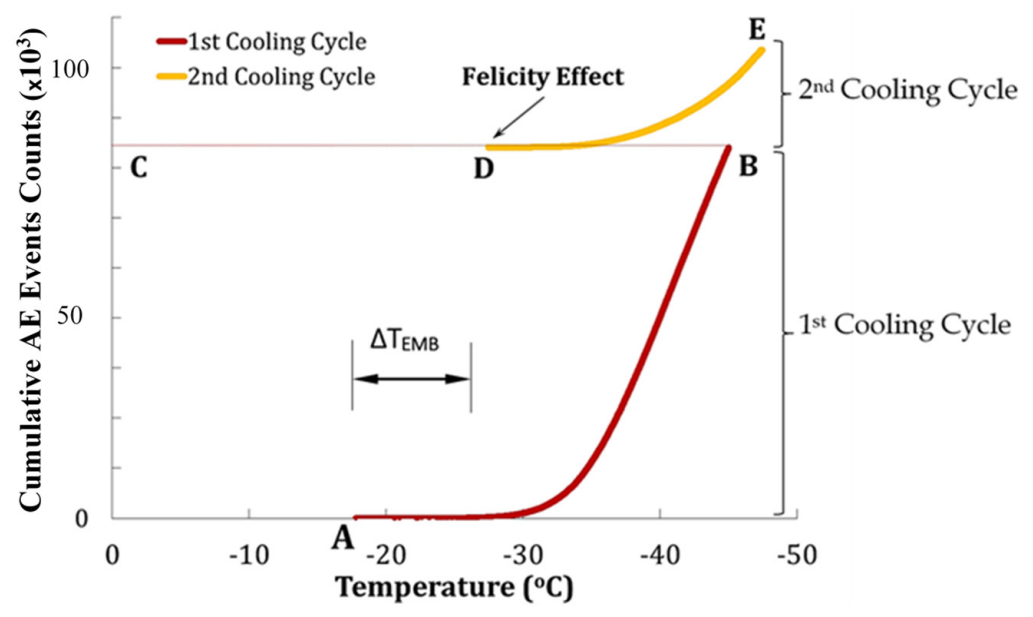

Figure 14. Typical AE test results of thermal cyclic loading of laboratory samples. Please note the presence of the Felicity effect as a result of self-healing. 
Observation of the Felicity effect instead of the Kaiser effect in asphalt pavement materials suggests partial healing of microcracks in the material. Due to the adhesive nature of asphalt concrete materials, some level of micro-crack self-healing may take place within material during thermal unloading. The amount of micro-crack self-healing may vary depending on the binder chemical composition and upon the level of oxidative aging of the asphalt mixture, as well as on the ambient temperature and presence of moisture. This means that in thermal cyclic loading of adhesive materials such as asphalt mixtures with high potential of micro-crack healing, the Felicity effect is the one that would occur rather than the Kaiser effect. Here, the Felicity Ratio (FR) is defined as the ratio of temperature at point $\mathrm{D}$ to the temperature of point $\mathrm{B}$, the lowest temperature of the first cooling cycle. The average Felicity ratio for tested asphalt concrete materials was around $0.648[44,45]$. To better quantify crack healing of asphalt material, a new parameter called the "Healing Index" was introduced and defined by the following equation.

$$
\text { Healing Index }(\%)=100(1-F R)
$$

The Healing Index was used as an indication of the amount of healing that may occur in asphalt concrete between the loading cycles over the period of thermal unloading. Depending on the sample temperature (i.e., thermal cycle), type of asphalt binder, and presence of moisture, the Healing Index of asphalt mixture ranges from $0 \%$ (no healing) to $100 \%$ (fully healed). For the mixtures tested, the average Healing Index of the tested samples was around $35 \%$, which indicates partial healing of the asphalt concrete during the rest period between the first and second cooling cycles. Results also showed that the oxidative aging adversely affected the thermal cracking healing capability of asphalt pavements, as the asphalt materials with higher level of oxidative aging exhibited lower Healing Index. For additional information, the readers are referred to Reference [44].

\section{Restoring Original Low-Temperature Performance to Aged Asphalt Pavements}

Oxidative aging leads to an increase in stiffness, loss of ductility and cohesion of binders, and warmer embrittlement temperatures, see Table 1 and Figure 8. As a result, oxidative aging lowers the resistance to fracture of oxidized mixtures as compared to their virgin state [37,46-48]. To restore the crack-resistant state of oxidized asphalt concrete pavements, measures such as pavement surface milling and/or the application of rejuvenators are taken. Asphalt rejuvenators are asphalt additives and modifiers that are used to revitalize, provide sealing, and restore the physical and chemical properties of the aged asphalt concrete [49-51]. Rejuvenators address the issue of oxidative hardening by softening the aged asphalt binder through restoration of the asphaltenes to maltenes ratio [6]. After applying a thin layer of rejuvenator over the top surface of pavement, the rejuvenator penetrates the asphalt concrete using the pore and tortuosity structure via gravity and capillary action, and diffuses through the asphalt concrete to chemically react with the asphalt binder. The rejuvenator/binder reaction restores the binder's material properties to its original state, i.e., the material properties of the virgin material. As the asphalt binder is softened, it also increases its adhesive properties and reduces the susceptibility of the asphalt pavement to thermal cracking.

As described by Brown [49], with the exception of visual inspection, there is no standardized method to evaluate the performance of rejuvenators when applied in the field. Currently, the ability of rejuvenators to improve pavements' durability is typically evaluated by (1) estimating the penetration in samples at $25^{\circ} \mathrm{C}$ using asphalt binder extracted from untreated and treated cores, (2) comparing the viscosity at $60{ }^{\circ} \mathrm{C}$ of asphalt binder samples extracted from untreated and treated cores, and (3) comparing the percentage of aggregate loss when untreated and treated samples are subjected to a pellet abrasion test. Mainly because these tests are cumbersome and time consuming, they are not often used. Here, AE source location is used to characterize and evaluate the rejuvenators' ability to restore mixtures to their original low-temperature performance grading, i.e., their original crack resistant state. 
Because of the granular nature of asphalt concrete mixtures, the Geiger's iterative source location technique [51,52] was used to accurately locate the source of each event. The Geiger's method is the application of the Gauss-Newton algorithm, which requires data from at least four AE sensors to build the following arrival time function of the $i$ th sensor:

$$
f_{i}(x, y, z, t)=T_{S}+\frac{1}{v} \sqrt{\left(x_{i}-X_{S}\right)^{2}+\left(y_{i}-Y_{S}\right)^{2}+\left(z_{i}-Z_{S}\right)^{2}}
$$

in which $\left(X_{s}, Y_{s}, Z_{s}\right)$ represent the spatial coordinates of the source, $\left(x_{i}, y_{i}, z_{i}\right)$ represent the coordinates of the ith sensor, $v$ is the known wave velocity, and $T_{S}$ and $t_{i}$ are the unknown source event occurring time and the known receiving time by the $i$ th sensor, respectively. Equation (3) can be expanded using Taylor series at a point $\left(x_{0}, y_{0}, z_{0}\right)$, near the actual source, resulting in Equation (4):

$$
f_{i}(x, y, z, t)=f_{i}\left(x_{0}, y_{0}, z_{0}, t_{0}\right)+\epsilon_{i}
$$

in which $\epsilon_{i}$, the residual term, a.k.a. the correction vector, is the difference between the calculated arrival time and the observed arrival time with respect to the $i$-th sensor. It can be calculated using the first order derivatives of the arrival time function. By going through several iterations of Equation (5), the Geiger's method tries to minimize the correction vector.

$$
\epsilon_{i}=\frac{\partial f_{i}}{\partial x} \delta x+\frac{\partial f_{i}}{\partial y} \delta y+\frac{\partial f_{i}}{\partial z} \delta z+\frac{\partial f_{i}}{\partial t} \delta t
$$

Gyratory compacted specimens with 5.6\% of asphalt content were made using PG64-22 binder and nominal maximum aggregate size (NMAS) of $19 \mathrm{~mm}$. Some specimens were short-term aged for two hours at $155^{\circ} \mathrm{C}$ to simulate aging during plant production, and other specimens were aged for $36 \mathrm{~h}$ at $155^{\circ} \mathrm{C}$ (in addition to the short term aging). The specimens' aging was performed on loose mixtures, which were hand-stirred every $12 \mathrm{~h}$ to ensure uniform aging. Each gyratory compacted specimen was then cut into two $5-\mathrm{cm}$ tall cylindrical specimens with a diameter of $150 \mathrm{~mm}$, for a total of eight test specimens. Figure 15 shows one of these specimens with four AE sensors coupled to the top and bottom plane surfaces of the cylindrical specimen. To avoid numerical instability, the sensors placed on the bottom of the specimens have a $45^{\circ}$ offset angle with respect to the sensors coupled on the top surface.

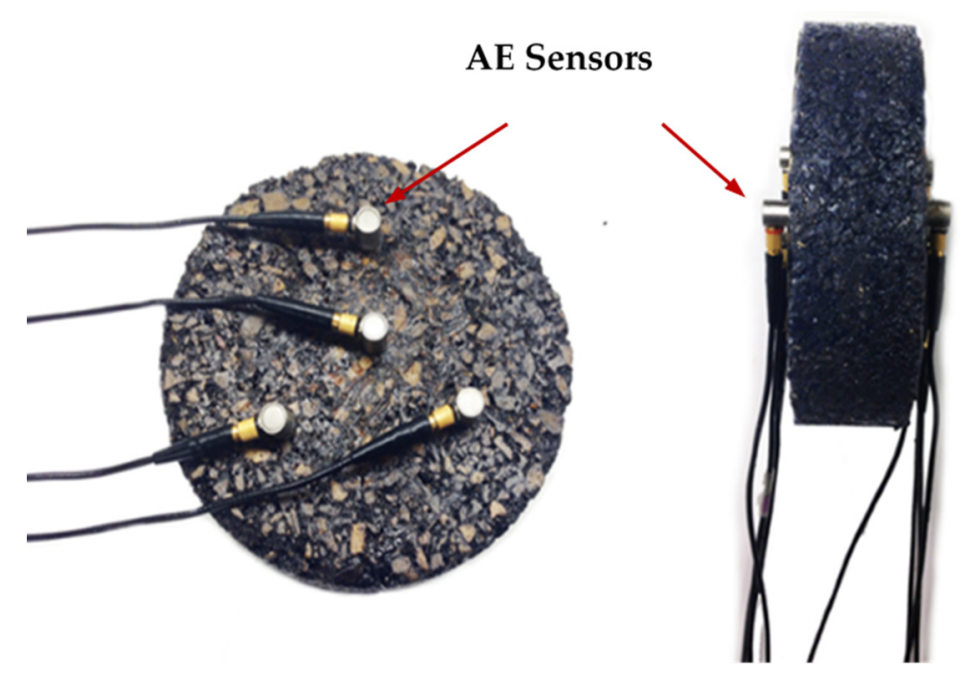

Figure 15. AE source location in asphalt mixture samples using eight piezoelectric sensors with four sensors mounted on each plane side of the specimen. To avoid numerical instabilities, the sensor pattern placed in one surface has a $45^{\circ}$ offset angle with respect to the pattern of the opposite surface. 
Out of the eight 5-cm tall specimens, two long term specimens (aged for $36 \mathrm{~h}$ ) and two short term aged, i.e., virgin specimens, were tested using $\mathrm{AE}$, and used as the control samples. The other four specimens were treated by spreading a thin layer of rejuvenator (e.g., Reclamite) on the top surface of the specimens in the amount of $10 \%$ by weight of the binder. The four specimens were then stored for a prescribed dwell time of two, four, six, and eight weeks before conducting AE tests. After each dwell time, each specimen was then tested using the same AE source location procedure used to test the $36 \mathrm{~h}$ and two hours aged specimens, which allowed the estimation of the embrittlement temperatures throughout the specimen thickness.

Figure 16 shows the combined embrittlement temperatures versus thickness results for all asphalt specimens using the Geiger's iterative source location method. Figure 16 shows that the embrittlement temperature of 36 -h aged samples $\left(-13^{\circ} \mathrm{C}\right)$ is warmer than that of virgin, i.e., short-term aged sample $\left(-22{ }^{\circ} \mathrm{C}\right)$ due to oxidative aging. Figure 16 clearly shows that after two weeks of dwell time, all of the specimen embrittlement temperature material properties have been recuperated. After six and eight weeks, the achieved embrittlement temperatures far exceeded the embrittlement temperatures of the virgin specimens. In addition, Figure 16 also shows that for the dwell times of two and four weeks, the method also captured the gradation the embrittlement temperature properties throughout the thickness, mainly because the rejuvenator has had additional time to act on the top material layers. This is an indication that the used AE approach can be used to evaluate the graded embrittlement temperature properties of aged pavements in the field, see Figure 3b, Figure 8, and Table 1. These findings shows that this AE approach may be used to intelligently select the best maintenance strategies by assessing and optimizing the relative amount of milling and surface replacement, or the levels of rejuvenation needed to restore pavement to the original crack-resistant state. The AE results using source location are consistent with the results obtained using non-collinear ultrasonic wave mixing $[48,53,54]$.

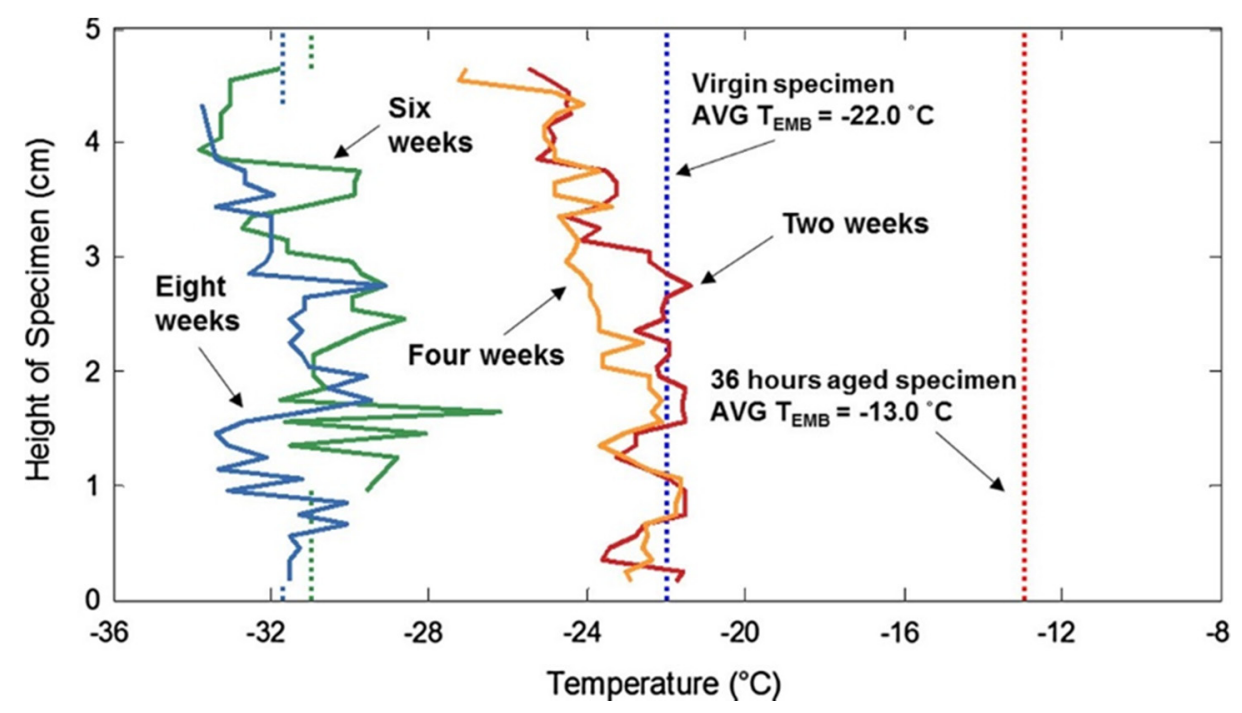

Figure 16. Average measured embrittlement temperatures of rejuvenator-treated oven-aged asphalt concrete samples (for $36 \mathrm{~h}$ at $135^{\circ} \mathrm{C}$ ) after dwell times of 2, 4, 6, and 8 weeks. For comparison, the embrittlement temperatures of the short-term aged (i.e., virgin) samples and of oven-aged samples for $36 \mathrm{~h}$ at $135{ }^{\circ} \mathrm{C}$ of $-22.0^{\circ} \mathrm{C}$ and $-13{ }^{\circ} \mathrm{C}$, respectively, are also noted (see dotted and dashed lines respectively). Note that after two weeks of dwell time, the unaged mixture embrittlement temperature was already restored. Also, at 2 and 4 weeks of dwell time, the top material layers have a cooler embrittlement temperature, because the rejuvenator had more time to act upon the binder. 


\section{Conclusions}

An acoustic emission based testing approach was developed to address the shortage for accurate and reliable techniques to evaluate the low-temperature cracking performance of asphalt pavements. The developed AE approach was successfully implemented to evaluate and characterize both virgin, short-term, and long-term asphalt binders and asphalt concrete materials. The extension of AE-based method to asphalt concrete materials opened the door for the use of the technique for asphalt pavement condition assessment. The AE technique was also successfully employed in different areas such as evaluating asphalt pavements containing recycled materials such as RAP or RAS, assessing the effect of cooling cycles upon the structural integrity of pavements, and evaluating the thermal cracking performance of graded, i.e., aged asphalt pavements.

The developed acoustic emission-based testing technique appears to be a viable approach for the characterization of low-temperature cracking of asphalt pavements, and it could be a powerful tool for enhancing pavement sustainability when used for preventive maintenance and rehabilitation. This technique could yield a significant payoff to practice for both up-stream and down-stream suppliers and producers of asphalt concrete binders. Up-stream supplies of polymer, chemical, and other additives (warm-mix additives, antistrip agents) could use the proposed technology to rapidly assess the low-temperature characteristics of trial formulations, and could quickly assess the compatibility of blended additive systems. Asphalt mixture designers could also use the technology to verify binder grade selection, optimize the amount of recycled materials, and/or select the appropriate binder grade to use in RAP and RAS mixtures, assess and design warm-mixtures, or verify compatibility when multiple additives are used. Pavement owners may be able to use the AE approach for quality assurance of binders and mixtures, for the periodic assessment of pavement conditions, and for the scheduling of preventive maintenance and rehabilitation, when pavement cracking is of concern.

Acknowledgments: The authors are very grateful for the support provided by the NCHRP Innovations Deserving Exploratory Analysis (IDEA) Program (managed by Inam Jawed) under Project 144 and Project 170 [36,37], which led to several of the authors' articles cited in this paper. Without this support, the current review paper would not have been possible. The authors are also grateful for the partial support (Contract Number W912HZ-16-C-0006) of the US Airforce Civil Engineering Center (AFCEC), including the technical support of our technical contacts George Vansteenburg and Jeb S. Tingle. Their support and many technical discussions was invaluable. The authors are also very grateful to the Missouri Department of Transportation for their support of current work.

Author Contributions: The authors contributed equally to the manuscript.

Conflicts of Interest: The authors declare no conflicts of interest.

\section{References}

1. Kim, Y.R. Modeling of Asphalt Concrete, McGraw-Hill Construction; ASCE Press: New York, NY, USA, 2008; ISBN-13 978-0071464628.

2. Apeagyei, A.K.; Buttlar, W.G.; Reis, H. Estimation of low-temperature embrittlement for asphalt binders using an acoustic emission approach. INSIGHT 2009, 51, 129-136. [CrossRef]

3. Behnia, B. An Acoustic Emission-Based Test to Evaluate Low Temperature Behavior of Asphalt Materials. Ph.D. Thesis, University of Illinois at Urbana-Champaign, Urbana, IL, USA, 2013.

4. Behnia, B.; Buttlar, W.G.; Reis, H. Nondestructive evaluation of thermal damage in asphalt concrete materials. J. Test. Eval. ASTM 2017, 45, 1948-1958.

5. Islam, S.; Buttlar, W. Effect of pavement roughness on user costs. Transp. Res. Rec. J. Transp. Res. Board 2012, 2285, 47-55. [CrossRef]

6. Petersen, J. A review of the fundamentals of asphalt oxidation. In Transportation Research Circular Number E-C140; Transportation Research Board: Washington, DC, USA, 2009.

7. Mirza, M.W.; Witczak, M.W. Development of a global aging system for short term and long term aging of asphalt cements. Assoc. Asph. Paving Technol. J. 1995, 64, 393-430. 
8. AASHTO MP1. Standard Specification for Performance-Graded Asphalt Binder; American Association of State Highway and Transportation Officials (AASHTO): Washington, DC, USA, 1998.

9. AASHTO TP1. Standard Specification for Determining the Flexural Creep Stiffness of Asphalt Binder Using the Bending Beam Rheometer (BBR); American Association of State Highway and Transportation Officials (AASHTO): Washington, DC, USA, 1999.

10. AASHTO MP1A. Standard Specification for Determining Low-Temperature Performance Grade of Asphalt Binders; American Association of State Highway and Transportation Officials (AASHTO): Washington, DC, USA, 2001.

11. FHWA-SA-95-003. Background of Superpave Asphalt Mixture Design and Analysis; US Department of Transportation, Federal Highway Administration: Washington, DC, USA, 1995.

12. Asphalt Institute Superpave Series No 2 (SP-2). Superpave Mix Design; Asphalt Institute: Lexington, KY, USA, 1996.

13. Bouldin, M.G.; Dongre, R.; Rowe, G.M.; Sharrock, M.J.; Anderson, D.A. Predicting thermal cracking of pavements from binder properties: Theoretical basis and field validation. Assoc. Asph. Pavement Technol. 2000, 69, 455-496.

14. Dongre, R.; Bouldin, M.G.; Anderson, D.A.; Reinke, G.; D'Angelo, J.; Kluttz, R.O.; Zanzotto, L. Overview of the Development of the New Low-Temperature Binder Specification; Technical Report; Federal Highway Administration Binder Expert Task Group: Washington, DC, USA, 1999.

15. Kim, S.S. Direct measurement of asphalt binder thermal cracking. J. Mater. Civ. Eng. 2000, 17, 632-639. [CrossRef]

16. Kim, S.S.; Wysong, Z.D.; Kovach, J. Low-temperature thermal cracking of asphalt binder by asphalt binder cracking device. Transp. Res. Record 2006, 1962, 28-35. [CrossRef]

17. Roy, D.; Hesp, S.A.M. Low-temperature binder specification development: Thermal stress restrained specimen testing of asphalt binders and mixtures. Transp. Res. Record 2001, 1766, 7-14. [CrossRef]

18. Shenoy, A. Single-event cracking temperature of asphalt pavements directly from bending beam rheometer data. J. Transp. Eng. 2000, 128, 465-471. [CrossRef]

19. Marasteanu, M.; Zofka, A.; Turos, M.; Li, X.; Velasquez, R.; Li, X.; Williams, C.; Bausano, J.; Buttlar, W.; Paulino, G.; et al. Investigation of Low Temperature Cracking in Asphalt Pavements; Report No. 776; Minnesota Department of Transportation, Research Services MS 330: St. Paul, MN, USA, 2007.

20. Marasteanu, M.; Buttlar, W.; Bahia, H.; Williams, C.; Moon, K.H.; Teshale, E.Z.; Falchetto, A.C.; Turos, M.; Dave, E.; Paulino, G.; et al. Investigation of Low Temperature Cracking in Asphalt Pavements National Pooled Fund Study-Phase II. 2012. Available online: https://www.dot.state.mn.us/research/TS/2012/ 2012-23.pdf (accessed on 20 February 2018).

21. Khosla, N.P.; Goetz, W.H. Tensile Characteristics of Bituminous Mixtures as Affected by Modified Binders; Joint Highway Research Project; Purdue University and the Indiana State Highway Commission: West Lafayette, Indiana, 1979.

22. Valkering, C.P.; Jongeneel, D.J. Acoustic emission for evaluating the relative performance of asphalt mixes under thermal loading conditions (With Discussion). J. Assoc. Asph. Paving Technol. 1991, 60, 160-187.

23. Hesp, S.; Terlouw, T.; Vonk, W. Low temperature performance of SBS-modified asphalt mixes. Asph. Paving Technol. 2000, 69, 540-573.

24. Li, X.; Marasteanu, M. Evaluation of the low temperature fracture resistance of asphalt mixtures using the semi-circular bend test (with discussion). J. Assoc. Asph. Paving Technol. 2004, 73, 401-426.

25. Li, X.; Marasteanu, M.O. Investigation of low temperature cracking in asphalt mixtures by acoustic emission. Road Mater. Pavement Des. 2006, 7, 491-512. [CrossRef]

26. Li, X.; Marasteanu, M.O.; Iverson, N.; Labuz, J.F. Observation of crack propagation in asphalt mixtures with acoustic emission. Transp. Res. Record J. Transp. Res. Board 2006, 1970, 171-177. [CrossRef]

27. Li, X.; Marasteanu, M.O.; Turos, M. Study of low temperature cracking in asphalt mixtures using mechanical testing and acoustic emission methods (With Discussion). J. Assoc. Asph. Paving Technol. 2007, 76, 427-453.

28. Li, X.; Marasteanu, M. The fracture process zone in asphalt mixture at low temperature. Eng. Fract. Mech. 2010, 77, 1175-1190. [CrossRef] 
29. Nesvijski, E.; Marasteanu, M. Wavelet transform and its applications to acoustic emission analysis of asphalt cold cracking. The e-Journal of Nondestructive Testing $\mathcal{E}$ Ultrasonics 2001, 12, 6. Available online: http:/ / citeseerx.ist.psu.edu/viewdoc/download?doi=10.1.1.128.1542\&rep=rep1\&type=pdf (accessed on 20 February 2018).

30. Nesvijski, E.; Marasteanu, M. Spectral analysis of acoustic emission of cold cracking asphalt. The e-Journal of Nondestructive Testing $\mathcal{E}$ Ultrasonics 2006, 11, 10. Available online: http: / / citeseerx.ist.psu.edu/viewdoc/ download?doi=10.1.1.216.6582\&rep=rep1\&type=pdf (accessed on 20 February 2018).

31. Behnia, B.; Buttlar, W.G.; Reis, H.; Apeagye, A.K. Determining the embrittlement temperature of asphalt binders using an acoustic emission approach. Proceedings of Structural Materials Technology Conference, New York, NY, USA, 16 August 2010; pp. 318-325.

32. Behnia, B.; Dave, E.V.; Buttlar, W.G.; Reis, H. Characterization of embrittlement temperature of asphalt materials through implementation of acoustic emission technique. Constr. Build. Mater. 2016, 111, 147-152. [CrossRef]

33. Behnia, B.; Buttlar, W.G.; Reis, H. Nondestructive low-temperature cracking characterization of asphalt materials. J. Mater. Civ. Eng. 2016, 29, 04016294. [CrossRef]

34. Hill, B.; Oldham, D.; Behnia, B.; Fini, E.; Buttlar, W.; Reis, H. Low-temperature performance characterization of biomodified asphalt mixtures that contain reclaimed asphalt pavement. Transp. Res. Record J. Transp. Res. Board 2013, 2371, 49-57. [CrossRef]

35. Hill, B.; Oldham, D.; Behnia, B.; Fini, E.H.; Buttlar, W.G.; Reis, H. Evaluation of low temperature viscoelastic properties and fracture behavior of bio-asphalt mixtures. Int. J. Pavement Eng. 2018, 19, 362-369. [CrossRef]

36. Buttlar, W.G.; Behnia, B.; Reis, H. An Acoustic Emission-Based Test to Determine Asphalt Binder and Mixture Embrittlement Temperature; Final Report, NCHRP IDEA Project No. 144; National Cooperative Highway Research Program: Washington, DC, USA, 2011.

37. Buttlar, W.G.; Reis, H.; Behnia, B. Development and Implementation of the Asphalt Embrittlement Analyzer; Final Report, NCHRP IDEA Project No. 170; National Cooperative Highway Research Program: Washington, DC, USA, 2015.

38. Behnia, B.; Buttlar, W.G.; Reis, H. Spiral cracking pattern in asphalt materials. Mater. Des. 2017, 116, 609-615. [CrossRef]

39. Behnia, B.; Dave, E.; Ahmed, S.; Buttlar, W.; Reis, H. Effects of recycled asphalt pavement amounts on low-temperature cracking performance of asphalt mixtures using acoustic emissions. Transp. Res. Record J. Transp. Res. Board 2011, 2208, 64-71. [CrossRef]

40. Dave, E.V.; Behnia, B.; Ahmed, S.; Buttlar, W.G.; Reis, H. Low temperature fracture evaluation of asphalt mixtures using mechanical testing and acoustic emissions techniques. J. Assoc. Asph. Paving Technol. 2011, 80, 193-220.

41. Hill, B.; Behnia, B.; Buttlar, W.G.; Reis, H. Evaluation of warm mix asphalt mixtures containing reclaimed asphalt pavement through mechanical performance tests and an acoustic emission approach. J. Mater. Civ. Eng. 2012, 25, 1887-1897. [CrossRef]

42. Hill, B.; Behnia, B.; Hakimzadeh, S.; Buttlar, W.; Reis, H. Evaluation of low-temperature cracking performance of warm-mix asphalt mixtures. Transp. Res. Record J. Transp. Res. Board 2012, 2294, 81-88. [CrossRef]

43. Arnold, J.W.; Behnia, B.; McGovern, M.E.; Hill, B.; Buttlar, W.G.; Reis, H. Quantitative evaluation of low-temperature performance of sustainable asphalt pavements containing recycled asphalt shingles (RAS). Constr. Build. Mater. 2014, 58, 1-8. [CrossRef]

44. Behnia, B.; Buttlar, W.G.; Reis, H. Cooling cycle effects on low temperature cracking characteristics of asphalt concrete mixture. Mater. Struct. 2014, 47, 1359-1371. [CrossRef]

45. Hellier, C.J. Handbook of Nondestructive Evaluation; McGraw-Hill: New York, NY, USA, 2001; ISBN 978-0-070-2812-19.

46. McGovern, M.E.; Behnia, B.; Buttlar, W.G.; Reis, H. Characterization of oxidative ageing in asphalt concrete-Part 1: Ultrasonic velocity and attenuation measurements and acoustic emission response under thermal cooling. Insight-Non-Destr. Test. Cond. Monit. 2013, 55, 596-604. [CrossRef]

47. McGovern, M.E.; Behnia, B.; Buttlar, W.G.; Reis, H. Characterization of oxidative ageing in asphalt concrete-Part 2: Estimation of complex moduli. Insight-Non-Destr. Test. Cond. Monit. 2013, 55, 605-609. [CrossRef] 
48. McGovern, M.E.; Behnia, B.; Buttlar, W.G.; Reis, H. Use of nonlinear acoustic measurements for estimation of fracture performance of aged asphalt mixtures. Transp. Res. Rec. J. Transp. Res. Board 2017, 2631, 11-19. [CrossRef]

49. Brown, E.R. Preventive Maintenance of Asphalt Concrete Pavements; Report No. 88-1; National Center for Asphalt Technology: Auburn, AL, USA, 1988.

50. Sun, Z.; Farace, N.; Behnia, B. Buttlar, W.G.; Reis, H. Quantitative evaluation of rejuvenators to restore embrittlement temperatures in oxidized asphalt mixtures using acoustic emission. J. Acoust. Emiss. 2015, 33, 1-15.

51. Sun, Z.; Behnia, B.; Buttlar, W.G.; Reis, H. Acoustic emission quantitative evaluation of rejuvenators to restore embrittlement temperatures to oxidized asphalt mixtures. Constr. Build. Mater. 2016, 126, 913-923. [CrossRef]

52. Geiger, L. Probability method for the determination of earthquake epicenters from the arrival time only. Bull. St. Louis Univ. 1912, 8, 60-71.

53. McGovern, M.E.; Buttlar, W.G.; Reis, H. Effectiveness of rejuvenators on aged asphalt concrete using ultrasonic non-collinear subsurface wave-mixing. Mater. Eval. 2015, 73, 1367-1378.

54. McGovern, M.E.; Buttlar, M.E.; Reis, H. Damage Evaluation and Life Extension of Asphalt Pavements using Rejuvenators and Non-Collinear Ultrasonic Wave Mixing-A Review. ASME J. Nondestruct. Eval. Diagn. Progn. Eng. Syst. 2018, 1, 011002:1-011002:13. [CrossRef]

(C) 2018 by the authors. Licensee MDPI, Basel, Switzerland. This article is an open access article distributed under the terms and conditions of the Creative Commons Attribution (CC BY) license (http://creativecommons.org/licenses/by/4.0/). 